\title{
A Trial of Treatment for Acute Otorrhea in Children with Tympanostomy Tubes
}

\author{
Thijs M.A. van Dongen, M.D., Geert J.M.G. van der Heijden, Ph.D., \\ Roderick P. Venekamp, M.D., Ph.D., Maroeska M. Rovers, Ph.D., \\ and Anne G.M. Schilder, M.D., Ph.D.
}

\section{ABSTRACT}

\section{BACKGROUND}

Recent guidance for the management of acute otorrhea in children with tympanostomy tubes is based on limited evidence from trials comparing oral antibiotic agents with topical antibiotics.

\section{METHODS}

In this open-label, pragmatic trial, we randomly assigned 230 children, 1 to 10 years of age, who had acute tympanostomy-tube otorrhea to receive hydrocortisone-bacitracincolistin eardrops (76 children) or oral amoxicillin-clavulanate suspension (77) or to undergo initial observation (77). The primary outcome was the presence of otorrhea, as assessed otoscopically, 2 weeks after study-group assignment. Secondary outcomes were the duration of the initial otorrhea episode, the total number of days of otorrhea and the number of otorrhea recurrences during 6 months of follow-up, quality of life, complications, and treatment-related adverse events.

\section{RESULTS}

Antibiotic-glucocorticoid eardrops were superior to oral antibiotics and initial observation for all outcomes. At 2 weeks, 5\% of children treated with antibiotic-glucocorticoid eardrops had otorrhea, as compared with $44 \%$ of those treated with oral antibiotics (risk difference, -39 percentage points; 95\% confidence interval [CI], -51 to -26 ) and $55 \%$ of those treated with initial observation (risk difference, -49 percentage points; $95 \% \mathrm{CI},-62$ to -37 ). The median duration of the initial episode of otorrhea was 4 days for children treated with antibiotic-glucocorticoid eardrops versus 5 days for those treated with oral antibiotics $(\mathrm{P}<0.001)$ and 12 days for those who were assigned to initial observation $(\mathrm{P}<0.001)$. Treatment-related adverse events were mild, and no complications of otitis media, including local cellulitis, perichondritis, mastoiditis, and intracranial complications, were reported at 2 weeks.

\section{CONCLUSIONS}

Antibiotic-glucocorticoid eardrops were more effective than oral antibiotics and initial observation in children with tympanostomy tubes who had uncomplicated acute otorrhea. (Funded by the Netherlands Organization for Health Research and Development; Netherlands Trial Register number, NTR1481.)

From the Department of Epidemiology, Julius Center for Health Sciences and Primary Care (T.M.A.D., G.J.M.G.H., R.P.V., M.M.R., A.G.M.S.), and the Department of Otorhinolaryngology, Division of Surgical Specialties (G.J.M.G.H., R.P.V., A.G.M.S.), University Medical Center Utrecht, Utrecht, the Department of Social Dentistry, Academic Center for Dentistry Amsterdam, University of Amsterdam and VU University Amsterdam, Amsterdam (G.J.M.G.H.), and the Departments of Operating Rooms and Health Evidence, Radboud University Medical Center, Nijmegen (M.M.R.) - all in the Netherlands; and the Ear Institute, University College London, London (A.G.M.S.). Address reprint requests to Dr. van Dongen at t.m.a.vandongen@umcutrecht.nl.

N Engl J Med 2014;370:723-33. DOI: 10.1056/NEJMoa1301630

Copyright @) 2014 Massachusetts Medical Society. 
T HE INSERTION OF TYMPANOSTOMY TUBES is one of the most frequently performed surgical procedures in children. ${ }^{1}$ The main indications for this procedure are the restoration of hearing in children with persistent otitis media with effusion and the prevention of recurrences in children who have recurrent acute otitis media. ${ }^{2}$ Acute otorrhea is a common sequela in children with tympanostomy tubes, with reported incidence rates ranging from $26 \%$ in a metaanalysis of mainly observational studies (involving cases of clinically manifested otorrhea) to $75 \%$ in a randomized trial (which included asymptomatic and subclinical cases). ${ }^{3-5}$ Acute tympanostomy-tube otorrhea may be accompanied by foul odor, pain, and fever and can reduce the child's quality of life. ${ }^{6}$

Acute tympanostomy-tube otorrhea is thought to be the result of acute otitis media, whereby middle-ear fluid drains through the tube. Bacterial infection or superinfection of the middle ear is considered to be the predominant cause of acute otitis media and, hence, acute tympanostomy-tube otorrhea. 7 Treatment is therefore aimed at eradicating bacterial infection, with the options including broad-spectrum oral antibiotics and antibiotic eardrops with or without glucocorticoids. $^{8}$

The few trials comparing topical and oral antibiotics in children with this condition have had either small samples or methodologic limitations. ${ }^{8-11}$ The results have indicated that antibiotic or antibiotic-glucocorticoid eardrops are as effective as, or more effective than, oral antibiotics. In addition, topical treatment is unlikely to have systemic side effects and is thought by some to be less likely to cause microbial resistance of otopathogens than oral treatment.9,11,12 Since acute tympanostomy-tube otorrhea, like acute otitis media, may be self-limiting, initial observation may also be a good alternative. ${ }^{8,13,14}$ In this trial, we compared the effectiveness of three strategies for the management of acute tympanostomy-tube otorrhea in children: immediate treatment with antibiotic-glucocorticoid eardrops, immediate treatment with oral antibiotics, and initial observation.

\section{METHODS}

TRIAL CONDUCT AND OVERSIGHT

We performed an open-label, pragmatic, randomized, controlled trial. All the authors vouch for the completeness and accuracy of the data and analyses presented and for the fidelity of the trial to the study protocol. For details of the study design and statistical analysis plan, see the study protocol, available with the full text of this article at NEJM.org. The study was approved by the medical ethics committee of University Medical Center Utrecht. There was no commercial involvement in the trial.

\section{PATIENTS}

Children 1 to 10 years of age with symptoms of tympanostomy-tube otorrhea that had lasted for up to 7 days at the time of screening were eligible for trial participation. We excluded children with a body temperature of more than $38.5^{\circ} \mathrm{C}$, those who had received antibiotics during the previous 2 weeks, those who had had tympanostomy tubes placed within the previous 2 weeks, and those who had had an episode of otorrhea in the previous 4 weeks, three or more episodes in the previous 6 months, or four or more episodes in the previous year. We also excluded children with Down's syndrome, a craniofacial anomaly, a known immunodeficiency, or an allergy to the medications used in this study.

\section{PATIENT RECRUITMENT}

From June 2009 through May 2012, ear, nose, and throat surgeons and family physicians approached parents of children with tympanostomy tubes for study participation. Our research team contacted by telephone parents who expressed interest in participation. We informed them about the trial and checked inclusion and exclusion criteria. If a child had otorrhea at the time of the telephone call and was eligible for participation, a home visit was planned. If there were no current symptoms of otorrhea, parents were asked to contact the study center as soon as otorrhea occurred, so that a home visit by the study physician could be arranged.

\section{BASELINE ASSESSMENTS}

At the home visit, the study physician obtained written informed consent from parents, confirmed the presence of otorrhea otoscopically, took otorrhea samples for bacterial culture, and collected demographic and disease-specific data. Parents completed the Child Health Questionnaire (CHQ), ${ }^{15,16}$ which measures generic healthrelated quality of life, and the Otitis Media-6 (OM-6) questionnaire, ${ }^{17}$ which measures disease- 
specific health-related quality of life. Scores on the CHQ range from 1 to 35 across the four CHQ domains, with higher scores indicating better quality of life. Scores on the OM-6 questionnaire range from 6 to 42, with lower scores indicating better quality of life.

\section{STUDY-GROUP ASSIGNMENTS}

An independent data manager generated a randomization sequence (with the use of block sizes of six), with stratification according to age ( $<4$ years vs. $\geq 4$ years). The study physician accessed the trial randomization website at the conclusion of the home visit to obtain the study-group assignment. The randomization assignment was concealed and could not be predicted in advance of or during enrollment. The assignments were balanced in a 1:1:1 ratio for the three study groups: hydrocortisone-bacitracin-colistin eardrops (Bacicoline-B, Daleco Pharma) (administered as five drops, three times daily, in the discharging ear or ears for 7 days), oral amoxicillin-clavulanate suspension (30 mg of amoxicillin and $7.5 \mathrm{mg}$ of clavulanate per kilogram of body weight per day, divided into three daily doses administered orally for 7 days), or initial observation for 2 weeks (no assigned medication prescription to fill).

The study physician did not clean the ear canal, either at the baseline visit or at follow-up visits during the trial. Parents of children assigned to treatment with topical antibiotics were instructed to clean the outer ear of any discharge that could easily be removed with a tissue before applying the drops. In addition, they were instructed to tilt the child's head to one side (to an angle of approximately 90 degrees) when applying the eardrops and to have the child maintain this tilt for a few minutes to allow the drops to enter the ear canal. No other instructions, such as tragal pumping, were given. After the first follow-up visit, at 2 weeks, further management of otorrhea was left to the discretion of the child's ear, nose, and throat surgeon or family physician.

\section{FOLLOW-UP}

Parents kept a daily diary of treatment adherence, adverse events, and complications for 2 weeks and of ear-related symptoms for 6 months. At 2 weeks and at 6 months, the study physician visited the child at home, performed otoscopy, and checked and collected the parental diaries, and the parents completed the generic and diseasespecific health-related quality-of-life questionnaires.

\section{PRIMARY AND SECONDARY OUTCOMES}

The primary outcome, treatment failure, was defined as the presence of otorrhea in one or both ears, as observed otoscopically by the study physician 2 weeks after study-group assignment. Secondary outcomes were based on parental diaries and included duration of the initial otorrhea episode (from study-group assignment up to the first day of otorrhea that was followed by 7 or more days without otorrhea), total number of days with otorrhea and number of recurrent otorrhea episodes ( $\geq 1$ day with otorrhea after $\geq 7$ days without otorrhea) during 6 months of follow-up, complications, and treatment-related adverse events in the first 2 weeks. In addition, generic and disease-specific health-related quality of life was assessed at 2 weeks of follow-up.

\section{STATISTICAL ANALYSIS}

Using SPSS software, version 20 (SPSS), and Episheet software, October 2012 version, ${ }^{18}$ we performed all analyses according to the intention-to-treat principle and, except for treatmentrelated adverse events, the analyses were blinded with respect to study-group assignment. We imputed missing baseline data using unconditional medians. ${ }^{19}$

The main comparisons in our study were antibiotic-glucocorticoid eardrops versus oral antibiotics and antibiotic-glucocorticoid eardrops versus initial observation. For these comparisons, we calculated risk differences with $95 \%$ confidence intervals and numbers needed to treat in order to prevent one case of otorrhea at 2 weeks as assessed otoscopically. To control for multiple testing, topical treatment had to be superior in both comparisons. Assuming a conservative effect of approximately $60 \%, 3,9,11,20$ with a twosided threshold of $5 \%$ indicating statistical significance and with $90 \%$ statistical power, we estimated that 105 children would need to be enrolled in each group for the study to show a clinically relevant absolute difference of at least 20 percentage points between groups for this primary outcome.

We also calculated the risk difference and 95\% confidence interval for the comparison of oral antibiotics with initial observation for our primary outcome, as well as relative risks and 
95\% confidence intervals for all treatment comparisons. Using log-binomial regression analyses, we adjusted relative risks for possible confounding on the basis of a priori-defined clinically relevant and statistically significant differences in baseline characteristics.

For the secondary outcomes, we plotted Kaplan-Meier curves to determine the duration of the initial otorrhea episode in the three study groups, and we used log-rank tests to test for differences between groups. We calculated medians for the total number of days with otorrhea and the number of recurrent otorrhea episodes during 6 months of follow-up and for the change in the health-related quality-of-life scores at 2 weeks of follow-up. A change in the mean OM-6 score of 1.0 to 1.4 points is considered to constitute a moderate change, and a change of 1.5 or more points is considered to constitute a large change. ${ }^{6,17}$ We evaluated differences between groups using Mann-Whitney U tests.

\section{INTERIM ANALYSIS}

After 2 years of recruitment, 150 children with acute tympanostomy-tube otorrhea underwent randomization. This number was considerably lower than our target of 315 children. After consultation with the trial funder, the Netherlands Organization for Health Research and Development, we opted for an interim analysis (not planned a priori) to be performed by an independent data review committee. Committee members were unaware of the study-group assignments during the analysis and interpretation of the data.

The end point was defined a priori as a risk difference exceeding 20 percentage points. The end point was tested with the use of the Haybittle-Peto approach (with a $\mathrm{P}$ value of $<0.01$ considered to indicate statistical significance). Since safety (risk of harm) was not the reason for performing this interim analysis, patient enrollment continued. The interim analysis showed that the smallest risk difference for the primary outcome between the superior treatment and the other treatments was -32 percentage points $(95 \%$ confidence interval $[\mathrm{CI}],-48$ to $-17 ; \mathrm{P}<0.001)$. On May 21, 2012, the committee recommended that further recruitment to the trial be discontinued, that follow-up of all 230 children included thus far be completed, that blinding be maintained during data analyses, and that the results be reported according to accepted standards. ${ }^{21,22}$

RESULTS

\section{ENROLLMENT}

A total of 1133 potentially eligible children with tympanostomy tubes were registered for the trial; their parents were willing for them to participate in the trial in case acute tympanostomy-tube otorrhea developed. Parents of 886 children did not contact us or reported an otorrhea episode that did not fulfill the trial inclusion criteria (e.g., symptoms present for $>7$ days and otorrhea occurring within 2 weeks after tympanostomytube insertion).

Home visits were scheduled for 247 children with acute tympanostomy-tube otorrhea. Among these children, 17 had a body temperature of $38.5^{\circ} \mathrm{C}$ or higher or the tympanostomy tubes were no longer present (Fig. 1). A total of 230 children with acute tympanostomy-tube otorrhea were randomly assigned to receive antibiotic-glucocorticoid eardrops (76 children) or oral antibiotics (77) or to undergo initial observation (77). In the first 2 weeks, 71 children (93\%), 68 (88\%), and $61(79 \%)$ in the three groups, respectively, fully adhered to the assigned management strategy (Fig. 1).

\section{COMPLETENESS OF DATA}

The primary outcome was assessed in 228 children $(99 \%)$. Parental diaries were available for 221 children (96\%). In these diaries, information on the presence of otorrhea was available for $94 \%$ of all follow-up days (Fig. 1).

\section{STUDY POPULATION}

Demographic and clinical characteristics of the participants are provided in Table 1 , and in Table S1 in the Supplementary Appendix, available at NEJM.org. No clinically significant differences in baseline characteristics among the three study groups were observed. The indication for tube insertion (recurrent acute otitis media vs. persistent otitis media with effusion) and the bacteria cultured from otorrhea differed slightly among the groups (Table 1). The mean age of the children was 4.5 years, the median duration 


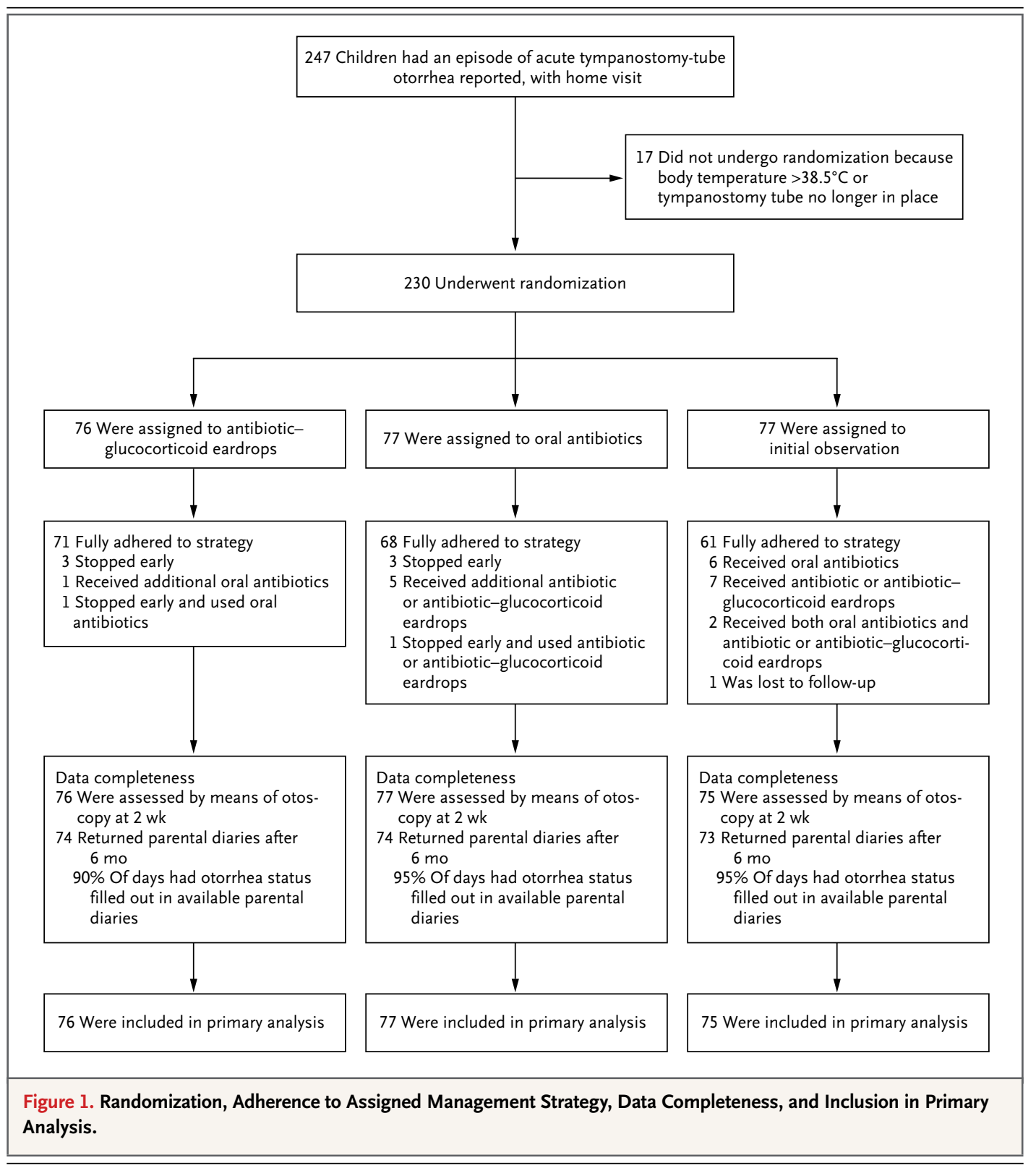

of otorrhea before study entry was 3 days, and 38 children (17\%) had otorrhea in both ears at baseline.

\section{PRIMARY ANALYSIS}

At 2 weeks, $5 \%$ of children treated with eardrops had otorrhea, as compared with $44 \%$ of those who received oral antibiotics (risk difference, -39 percentage points; $95 \% \mathrm{CI},-51$ to -26 ; number needed to treat, 3 ) and $55 \%$ of those who were assigned to initial observation (risk difference, -49 percentage points; $95 \% \mathrm{CI},-62$ to -37 ; number needed to treat, 2) (Table 2).

\section{SECONDARY ANALYSES}

At 2 weeks, children treated with oral antibiotics were less likely to have otorrhea than those who were assigned to initial observation, but this difference was not significant (risk difference, -11 percentage points; $95 \% \mathrm{CI},-27$ to 5). The relative 


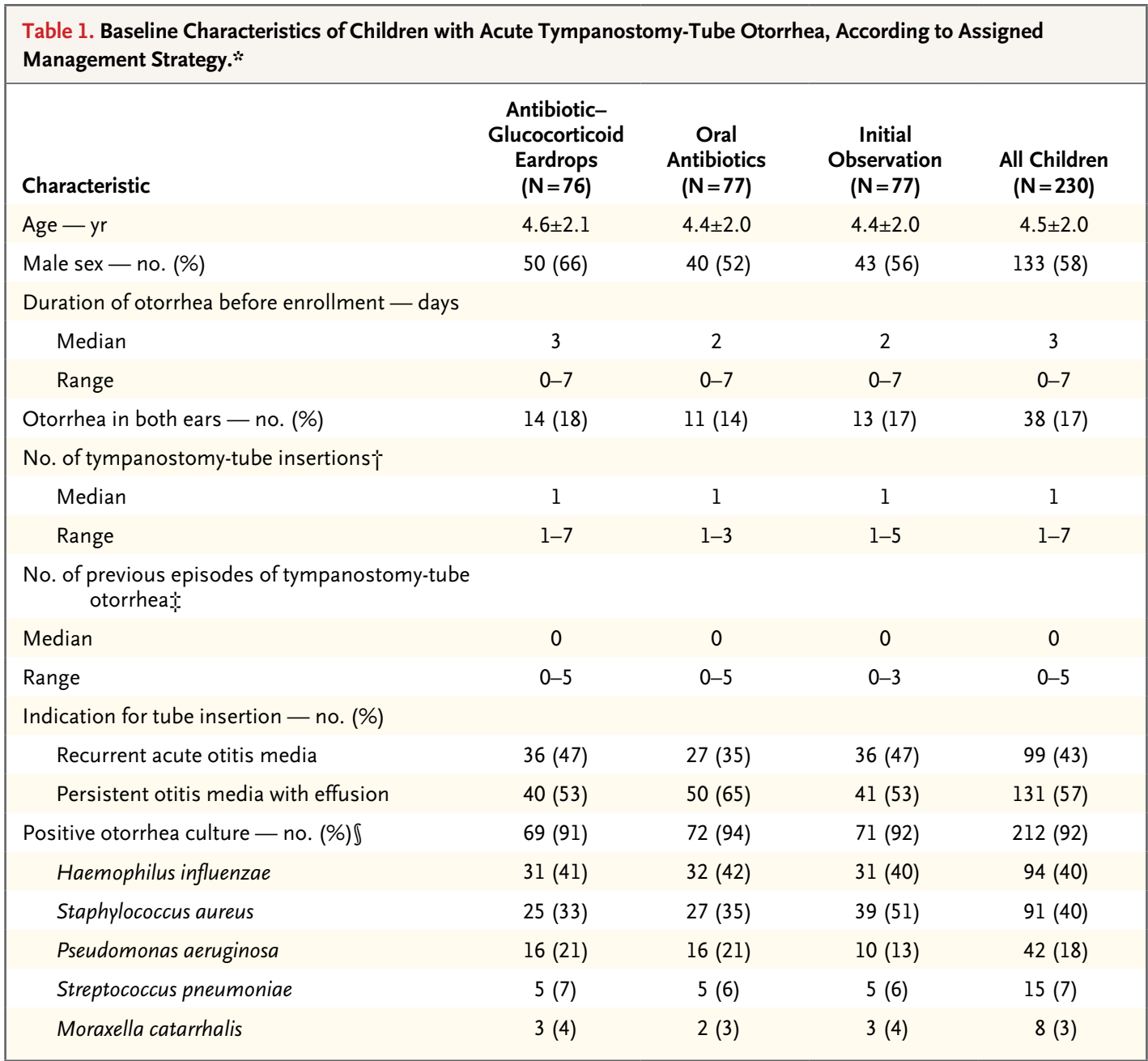

* Plus-minus values are means \pm SD. There were no significant differences between the treatment groups at baseline, except for the duration of otorrhea before enrollment $(P=0.04$ by the Kruskal-Wallis test) and the presence of Staphylococcus aureus in culture $(\mathrm{P}=0.05$ by the chi-square test). Data were missing on duration of otorrhea before enrollment for one child (1\%) in the study group that received oral antibiotics and on number of previous episodes of tympanostomy-tube otorrhea for three children: one child (1\%) who received oral antibiotics and two (3\%) who received antibiotic-glucocorticoid eardrops; we imputed the characteristics with the unconditional median. Complete details of the baseline characteristics are provided in Table Sl in the Supplementary Appendix.

$\uparrow$ The number of tympanostomy-tube insertions included the insertion of the current tympanostomy tubes.

$\checkmark$ The number of previous episodes of tympanostomy-tube otorrhea was restricted to the number of episodes with the current tympanostomy tubes.

$\int$ Multiple bacteria could be present in one sample, so percentages do not add up to 100.

risks with adjustment for small baseline differences did not differ substantially from the crude relative risks, which consistently favored antibiotic-glucocorticoid eardrops (Table 2).

The median duration of the initial episode of otorrhea was 4 days for children treated with eardrops versus 5 days for those treated with oral antibiotics $(\mathrm{P}<0.001)$ and 12 days for those assigned to initial observation $(\mathrm{P}<0.001)$ (Table 2 and Fig. 2). The median total number of days with otorrhea during 6 months of follow-up was 5 days for children receiving eardrops versus 13.5 days for those receiving oral antibiotics $(\mathrm{P}<0.001)$ and 18 days for those assigned to initial observation $(\mathrm{P}<0.001)$. The median number of recurrent episodes of otorrhea during 6 months of follow-up was 0 episodes for children treated with antibiotic eardrops versus 1 for those treated with oral antibiotics $(\mathrm{P}=0.03)$ and 1 for those assigned to initial observation $(\mathrm{P}=0.26)$. 


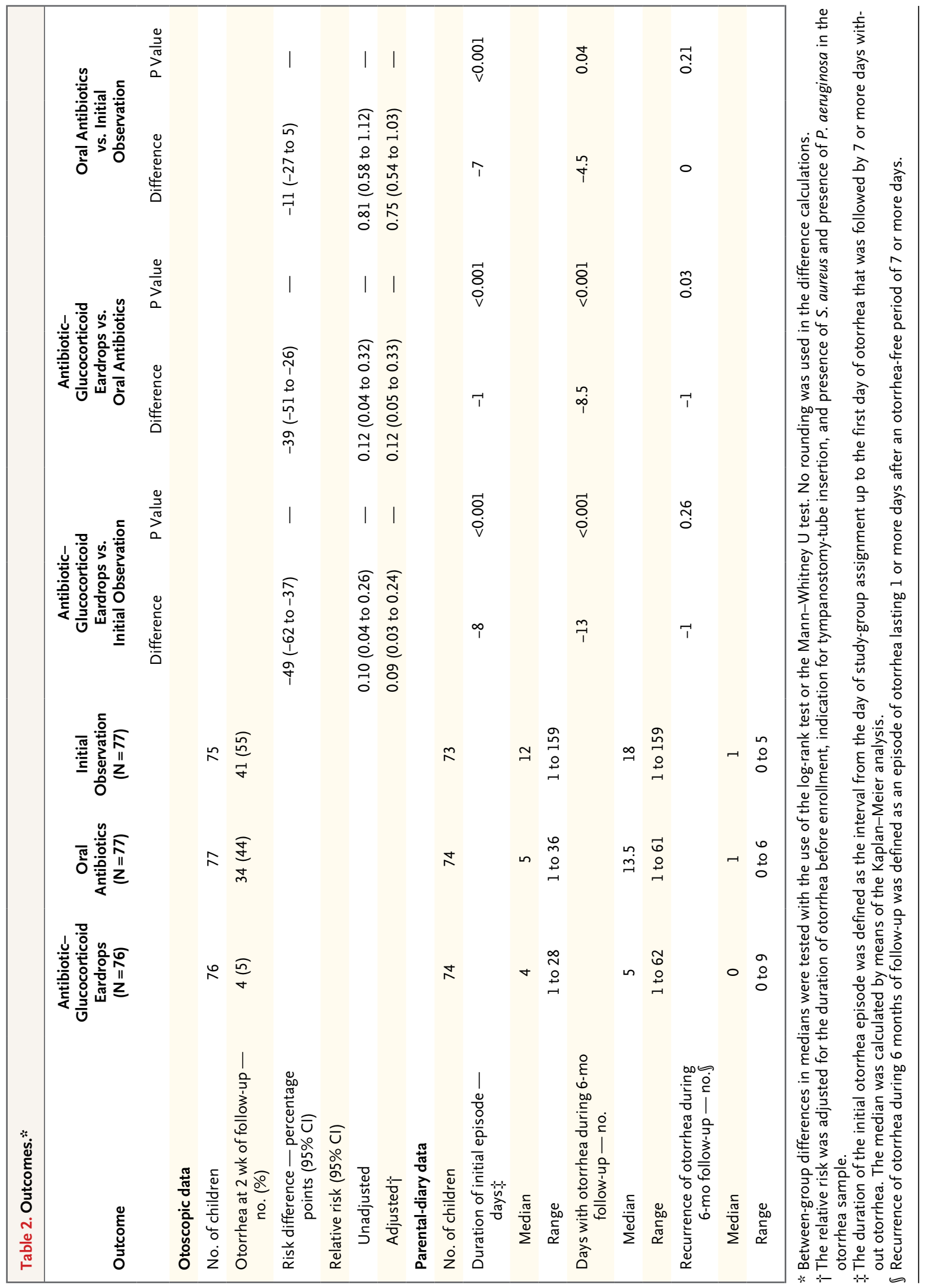

N ENGLJ MED 37O;8 NEJM.ORG FEBRUARY 20, 2014 


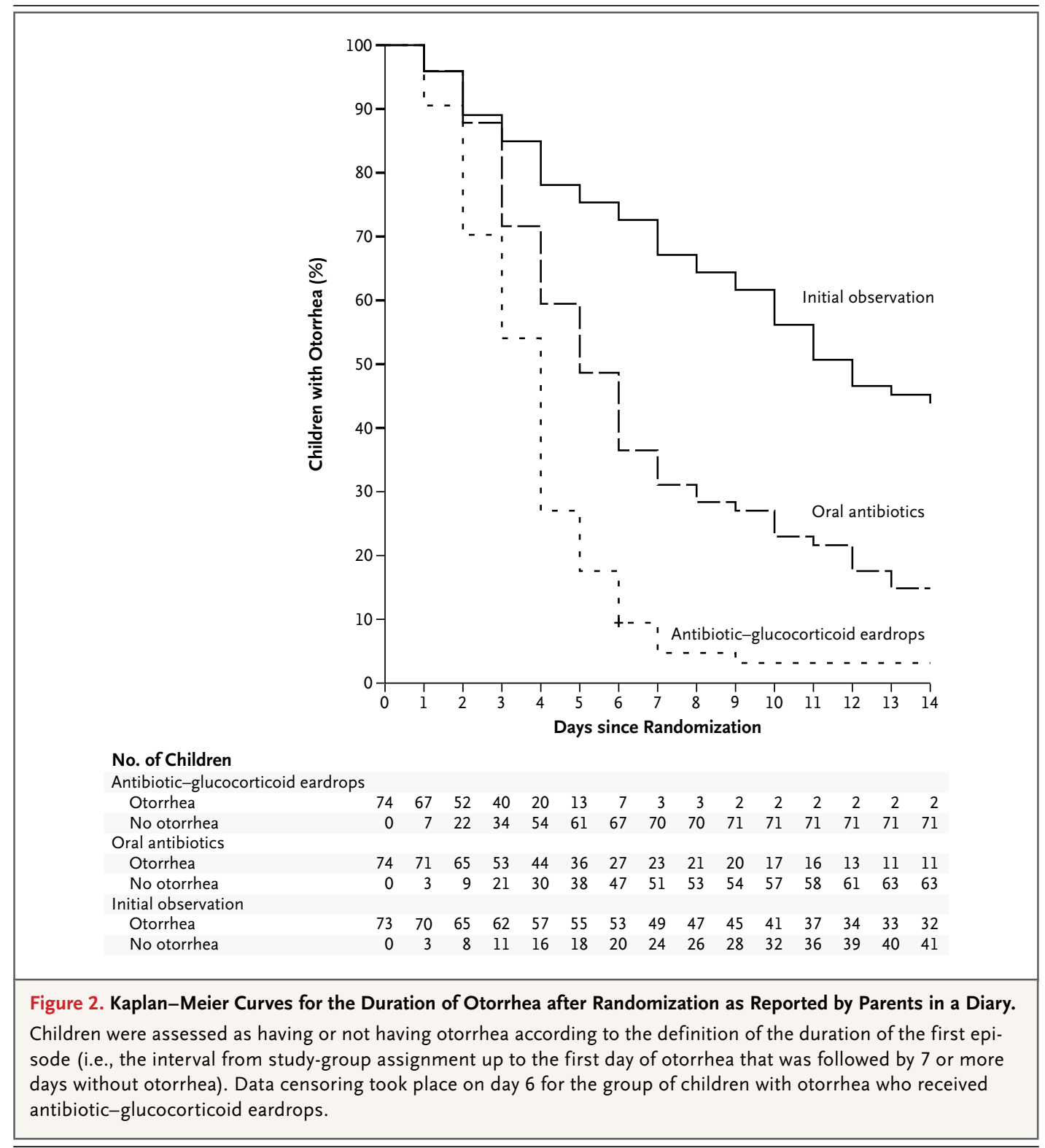

At baseline, the generic and disease-specific health-related quality-of-life scores indicated good quality of life and were similar across the groups. At 2 weeks of follow-up, the change in the generic health-related quality-of-life scores did not differ significantly among the study groups. The changes in the disease-specific health-related quality-of-life scores at 2 weeks were small but consistently favored eardrops (Tables S2 and S3 in the Supplementary Appendix).

\section{COMPLICATIONS AND ADVERSE EVENTS}

No complications of otitis media, including local cellulitis, perichondritis, mastoiditis, and intracranial complications, were reported during the first 2 weeks of follow-up (Table 3). A total of 16 children $(21 \%)$ who received eardrops had pain or discomfort when the drops were administered, and 2 (3\%) had a local rash. Gastrointestinal symptoms developed in 18 children (23\%) who received oral antibiotics, and rash developed 


\begin{tabular}{|c|c|c|c|c|c|c|}
\hline \multirow[t]{3}{*}{ Event } & $\begin{array}{l}\text { Antibiotic- } \\
\text { Glucocorticoid } \\
\text { Eardrops } \\
(N=76)\end{array}$ & $\begin{array}{c}\text { Oral } \\
\text { Antibiotics } \\
(\mathrm{N}=77)\end{array}$ & $\begin{array}{c}\text { Initial } \\
\text { Observation } \\
(\mathrm{N}=77)\end{array}$ & \multicolumn{3}{|c|}{ Absolute Risk Difference } \\
\hline & \multirow{2}{*}{\multicolumn{3}{|c|}{ no. of patients with event/total no. (\%) }} & $\begin{array}{l}\text { Antibiotic- } \\
\text { Glucocorticoid } \\
\text { Eardrops vs. } \\
\text { Initial } \\
\text { Observation }\end{array}$ & $\begin{array}{l}\text { Antibiotic- } \\
\text { Glucocorticoid } \\
\text { Eardrops vs. } \\
\text { Oral Antibiotics }\end{array}$ & $\begin{array}{c}\text { Oral Antibiotics } \\
\text { vs. Initial } \\
\text { Observation }\end{array}$ \\
\hline & & & & \multicolumn{3}{|c|}{ percentage points ( $95 \%$ confidence interval) } \\
\hline \multicolumn{7}{|l|}{ Adverse event within 2 wk } \\
\hline $\begin{array}{l}\text { Local discomfort or pain during } \\
\text { administration }\end{array}$ & $16 / 75(21)$ & $0 / 77$ & - & - & 21 (12 to 30$)$ & - \\
\hline Gastrointestinal discomfort & $0 / 75$ & $18 / 77(23)$ & - & - & $-23(-33$ to -14$)$ & - \\
\hline Rash & $2 / 75(3)$ & $3 / 77(4)$ & - & - & $-1(7$ to -4$)$ & - \\
\hline Oral candidiasis & $0 / 75$ & $0 / 77$ & - & - & $0(-)$ & - \\
\hline \multicolumn{7}{|l|}{ Adverse event within 6 mo } \\
\hline Otorrhea episode lasting $\geq 4 \mathrm{wk}$ & $1 / 74(1)$ & $5 / 74(7)$ & $12 / 73(16)$ & $-15(-24$ to -6$)$ & $-5(-12$ to 1$)$ & $-10(-20$ to 1$)$ \\
\hline Otorrhea episode lasting $\geq 12 \mathrm{wk}$ & $0 / 74$ & $0 / 74$ & $1 / 73(1)$ & $-1(-4$ to 1$)$ & $0(-)$ & $-1(-4$ to 1$)$ \\
\hline Serious adverse event within 2 wk $\dagger$ & $0 / 75$ & $0 / 77$ & $0 / 75$ & - & - & - \\
\hline
\end{tabular}

* Adverse events and serious adverse events occurring within 2 weeks after study-group assignment were reported by parents in a diary in which data related to the treatment strategy and complications of otitis media were collected, whereas those occurring within 6 months after studygroup assignment were derived from the parental diary on ear-related symptoms. No rounding was used in the difference calculations. $\uparrow$ Serious adverse events included complications of otitis media, such as local cellulitis, perichondritis, mastoiditis, and intracranial complication.

in 3 (4\%). During 6 months of follow-up, fewer children treated with eardrops had episodes of otorrhea that persisted for 4 weeks or more, as compared with those treated with oral antibiotics or those assigned to initial observation (Table 3).

\section{DISCUSSION}

In this pragmatic, randomized, controlled trial, we found that antibiotic-glucocorticoid eardrops were superior to oral antibiotics and to initial observation with respect to the primary outcome of otorrhea at 2 weeks, as assessed otoscopically, in children with tympanostomy tubes and acute otorrhea. Our secondary analyses support these findings. Approximately one in two children who were assigned to initial observation still had otorrhea at 2 weeks, and initial observation resulted in more days with otorrhea in the following months than did topical or oral antibiotics. This suggests that initial observation may not be an adequate management strategy in such children.
One previous trial compared the same management strategies - antibiotic-glucocorticoid eardrops, oral antibiotics, and observation but as prophylaxis for infection after tympanostomy-tube insertion. ${ }^{23}$ Three previous trials compared eardrops with oral antibiotics in the treatment of children with tympanostomy-tube otorrhea. ${ }^{9-11}$ In two of these trials, unlike ours, children with otorrhea that had persisted for up to 3 weeks (the exact duration of otorrhea at baseline was not reported) and those who had received treatment before study entry were allowed to participate. ${ }^{9,11}$ Both studies excluded children with positive cultures for group A streptococci or Pseudomonas aeruginosa from the analyses, which affected the applicability of these results to daily practice. In the third trial, which had a study population that was comparable to ours, 68 children with acute tympanostomy-tube otorrhea were randomly assigned to oral amoxicillin, ciprofloxacin eardrops, or saline rinsing of the ear canal. ${ }^{10}$ These investigators also found anti- 
biotic eardrops to be superior to the other treatments, but treatment-failure rates were higher than those we observed. The lower rates with topical treatment in our study may be explained by our use of eardrops containing both antibiotics and glucocorticoids and by our assessment of the treatment effect at 2 weeks rather than at 1 week. $^{24}$

A Finnish trial comparing the effectiveness of oral antibiotics with placebo in children with acute tympanostomy-tube otorrhea showed a shorter duration of otorrhea in children treated with oral antibiotics. ${ }^{20}$ During the study, the ear canal in participating children was cleaned by means of daily suction. Apart from uncertainty about the benefits of this additional daily intervention, the study results may not be applicable to daily clinical practice, in which it is neither accepted nor practical to perform daily suction. We did not find that oral antibiotics provided a greater benefit than initial observation with respect to the presence of otorrhea at 2 weeks, as assessed otoscopically, but we did find that the duration of the initial episode of otorrhea was shorter in children treated with oral antibiotics than in those assigned to initial observation.

Some aspects of our trial warrant further attention. First, the antibiotic-glucocorticoid eardrops we used are not routinely available outside the Netherlands and France. We chose hydrocortisone-bacitracin-colistin eardrops because they were the most widely used, commercially available eardrops for acute tympanostomy-tube otorrhea in the Netherlands that did not contain a potentially ototoxic aminoglycoside. The eardrops are active against most isolates of bacteria that cause acute tympanostomy-tube otorrhea (i.e., Streptococcus pneumoniae, Haemophilus influenzae, Moraxella catarrhalis, Staphylococcus aureus, and P. aeruginosa). Although evidence is lacking, we believe that any combination of antibiotic-glucocorticoid eardrops with similar antimicrobial activity, such as ciprofloxacin and dexamethasone, would be likely to have similar results. ${ }^{25}$

Second, the dose of the amoxicillin-clavulanate suspension that we used in our trial $(30 \mathrm{mg}$ of amoxicillin and $7.5 \mathrm{mg}$ of clavulanate per kilogram per day) is the recommended dose in the
Netherlands and in other European countries where antimicrobial resistance rates are low. ${ }^{10,20,26,27}$ Third, we used a pragmatic, nonblinded trial design to enhance the applicability of our findings to daily practice. ${ }^{28}$ Nevertheless, the outcomes assessed by the study physician were consistent with those reported by the parents in the diaries. Fourth, we believe that these diary data are accurate. We collected diaries, including information on the presence of otorrhea per follow-up day, for nearly all the children. In a study that was parallel to this trial, we found a high level of agreement between parents and physicians in the assessment of ear discharge in children after management of otorrhea. ${ }^{29}$

Fifth, at the design stage of this trial, we assumed an absolute reduction of 20 percentage points in the incidence of otorrhea after 2 weeks for one management strategy as compared with the others to be clinically relevant. The observed risk difference was actually twice as large, showing the importance of our findings for clinical practice. Finally, in a comparison of the children who were included in the trial with those who were not, we found similarities with regard to age, sex, and number of previous tympanostomy-tube insertions. Since the design of our trial allowed the inclusion of children who would be treated across health care settings, we believe our findings are applicable to children with uncomplicated acute tympanostomy-tube otorrhea presenting in either primary or secondary care.

Supported by a grant (170992502) from the Netherlands Organization for Health Research and Development Effects and Costs subprogram.

Dr. Schilder reports receiving grant support through her institution from GlaxoSmithKline. No other potential conflict of interest relevant to this article was reported.

Disclosure forms provided by the authors are available with the full text of this article at NEJM.org.

We thank the children and their parents who participated in the study; Pauline Winkler, Nelly van Eden, Lidian Izeboud, Dicky Mooiweer, and our team of medical students for administrative and practical support; the participating family physicians, especially Roger Damoiseaux, Marco Blanker, and Herman Kolk, and the ear, nose, and throat surgeons at the participating hospitals (see the Supplementary Appendix); Arno Hoes and Marc Bonten for advice regarding the design of the trial; Marloes van Beurden for data management; Rolf Groenwold and Chantal Boonacker for assistance with the interim analysis; and the members of the independent data review committee (Gerard Zielhuis, Hendrik Verschuur, and Rene Eijkemans). 
REFERENCES

1. Cullen K, Hall M, Golosinskiy A. Ambulatory surgery in the United States, 2006. National health statistics reports, no. 11, revised. Hyattsville, MD: National Center for Health Statistics, 2009.

2. Rosenfeld RM, Bluestone CD. Clinical efficacy of surgical therapy. In: Rosenfeld RM, Bluestone CD, eds. Evidence-based otitis media. 2nd ed. Hamilton, ON, Canada: B.C. Decker, 2003:227-40.

3. Kay DJ, Nelson M, Rosenfeld RM. Meta-analysis of tympanostomy tube sequelae. Otolaryngol Head Neck Surg 2001; 124:374-80.

4. van Dongen TM, van der Heijden GJ, Freling HG, Venekamp RP, Schilder AG. Parent-reported otorrhea in children with tympanostomy tubes: incidence and predictors. PLoS One 2013;8(7):e69062.

5. Ah-Tye C, Paradise JL, Colborn DK. Otorrhea in young children after tympanostomy-tube placement for persistent middle-ear effusion: prevalence, incidence, and duration. Pediatrics 2001;107:1251-8. 6. Rosenfeld RM, Bhaya MH, Bower CM, et al. Impact of tympanostomy tubes on child quality of life. Arch Otolaryngol Head Neck Surg 2000;126:585-92.

7. Peters BM, Jabra-Rizk MA, O'May GA, Costerton JW, Shirtliff ME. Polymicrobial interactions: impact on pathogenesis and human disease. Clin Microbiol Rev 2012; 25:193-213.

8. Vaile L, Williamson $\mathrm{T}$, Waddell A, Taylor G. Interventions for ear discharge associated with grommets (ventilation tubes). Cochrane Database Syst Rev 2006; 2:CD001933.

9. Dohar J, Giles W, Roland P, et al. Topical ciprofloxacin/dexamethasone superior to oral amoxicillin/clavulanic acid in acute otitis media with otorrhea through tympanostomy tubes. Pediatrics 2006;118(3): e561-e569.

10. Heslop A, Lildholdt T, Gammelgaard N, Ovesen T. Topical ciprofloxacin is superio to topical saline and systemic antibiotics in the treatment of tympanostomy tube otorrhea in children: the results of a ran- domized clinical trial. Laryngoscope 2010; 120:2516-20.

11. Goldblatt EL, Dohar J, Nozza RJ, et al. Topical ofloxacin versus systemic amoxicillin/clavulanate in purulent otorrhea in children with tympanostomy tubes. Int J Pediatr Otorhinolaryngol 1998;46:91-101. 12. Weber PC, Roland PS, Hannley M, et al. The development of antibiotic resistant organisms with the use of ototopical medications. Otolaryngol Head Neck Surg 2004;130:Suppl:S89-S94.

13. Rovers MM, Glasziou P, Appelman CL, et al. Antibiotics for acute otitis media: a meta-analysis with individual patient data. Lancet 2006;368:1429-35.

14. Isaacson G. Why don't those ear drops work for my patients? Pediatrics 2006; 118:1252-3.

15. Raat H, Botterweck AM, Landgraf JM, Hoogeveen WC, Essink-Bot ML. Reliability and validity of the short form of the Child Health Questionnaire for Parents (CHQ-PF28) in large random school based and general population samples. J Epidemiol Community Health 2005;59:75-82.

16. Hullmann SE, Ryan JL, Ramsey RR, Chaney JM, Mullins LL. Measures of general pediatric quality of life: Child Health Questionnaire (CHQ), DISABKIDS Chronic Generic Measure (DCGM), KINDL-R, Pediatric Quality of Life Inventory (PedsQL) 4.0 Generic Core Scales, and Quality of My Life Questionnaire (QoML). Arthritis Care Res (Hoboken) 2011;63:Suppl 11: S420-S430.

17. Rosenfeld RM, Goldsmith AJ, Tetlus L, Balzano A. Quality of life for children with otitis media. Arch Otolaryngol Head Neck Surg 1997;123:1049-54.

18. Episheet. Boston: Brigham and Women's Hospital and Harvard Medical School, 2012 (http://www.drugepi.org/ dope-downloads/-Episheet).

19. Donders AR, van der Heijden GJ, Stijnen T, Moons KG. A gentle introduction to imputation of missing values. J Clin Epidemiol 2006;59:1087-91.

20. Ruohola A, Heikkinen T, Meurman O,
Puhakka T, Lindblad N, Ruuskanen $\mathrm{O}$ Antibiotic treatment of acute otorrhea through tympanostomy tube: randomized double-blind placebo-controlled study with daily follow-up. Pediatrics 2003;111:1061-7. 21. Schulz KF, Altman DG, Moher D. CONSORT 2010 statement: updated guidelines for reporting parallel group randomised trials. J Clin Epidemiol 2010;63: 834-40.

22. Moher D, Hopewell S, Schulz KF, et al. CONSORT 2010 explanation and elaboration: updated guidelines for reporting parallel group randomised trials. J Clin Epidemiol 2010;63(8):e1-e37. [Erratum, J Clin Epidemiol 2012;65:351.]

23. Balkany TJ, Barkin RM, Suzuki BH, Watson WJ. A prospective study of infection following tympanostomy and tube insertion. Am J Otol 1983;4:288-91.

24. Roland PS, Anon JB, Moe RD, et al. Topical ciprofloxacin/dexamethasone is superior to ciprofloxacin alone in pediatric patients with acute otitis media and otorrhea through tympanostomy tubes. Laryngoscope 2003;113:2116-22.

25. U.S. National Library of Medicine. Daily Med (http://dailymed.nlm.nih.gov).

26. Easton J, Noble S, Perry CM. Amoxicillin/clavulanic acid: a review of its use in the management of paediatric patients with acute otitis media. Drugs 2003;63: 311-40.

27. Tähtinen PA, Laine MK, Huovinen $P$, Jalava J, Ruuskanen O, Ruohola A. A placebo-controlled trial of antimicrobial treatment for acute otitis media. $\mathrm{N}$ Engl J Med 2011;364:116-26.

28. Scott IA, Glasziou PP. Improving the effectiveness of clinical medicine: the need for better science. Med J Aust 2012;196: 304-8.

29. van Dongen TM, Schilder AG, Manders LA, van der Veen EL, van der Heijden GJ. Good agreement between parents and physician in the assessment of ear discharge in children. Pediatr Infect Dis J 2012;31:868-9.

Copyright (@) 2014 Massachusetts Medical Society.

JOURNAL ARCHIVE AT NEJM.ORG

Every article published by the Journal is now available at NEJM.org, beginning with the first article published in January 1812. The entire archive is fully searchable, and browsing of titles and tables of contents is easy and available to all.

Individual subscribers are entitled to free 24-hour access to 50 archive articles per year. Access to content in the archive is available on a per-article basis and is also being provided through many institutional subscriptions. 